\title{
COMMENT
}

\section{Meiobenthos and macrobenthos are discrete entities and not artefacts of sampling a size continuum: Comment on Bett (2013)}

\author{
R. M. Warwick ${ }^{1,2, *}$ \\ ${ }^{1}$ Plymouth Marine Laboratory, Prospect Place, West Hoe, Plymouth PL1 3DH, UK \\ ${ }^{2}$ Centre for Fish and Fisheries Research, School of Veterinary and Life Sciences, Murdoch University, 90 South Street, \\ Murdoch, Western Australia 6150, Australia
}

\begin{abstract}
Species size distributions for metazoan benthic invertebrates conform to the highly conservative bimodal pattern, regardless of the sieve mesh sizes or numbers of sieves used in their extraction. This pattern is not an artefact of sampling a size continuum as suggested by computer simulations using just 2 fixed mesh sizes in Bett (2013; Mar Ecol Prog Ser 487:1-6). Meiobenthos and macrobenthos are coherent entities, each with a distinct suite of functional attributes, and should not be regarded as a single unit for ecological modelling purposes.
\end{abstract}

KEY WORDS: Marine benthic invertebrates - Species size distributions - Meiobenthos . Macrobenthos · Functional traits

Resale or republication not permitted without written consent of the publisher

\section{Introduction}

Using computer simulations, Bett (2013) demonstrated what is perhaps intuitively obvious: that when size continua of perfect spheres (or a mixture of spheres and identically shaped cylinders in equal proportions) are sampled using sieves with 2 mesh sizes corresponding to those traditionally used by meiobenthic and macrobenthic researchers (i.e. 45 or $63 \mu \mathrm{m}$ and $500 \mu \mathrm{m}$ respectively), biomass size spectra are produced comprising 2 maxima with a trough between them. He therefore suggested that the previously proposed bimodal biomass spectrum across the meiobenthos-macrobenthos size range may be a sampling artefact. He went on to extrapolate this finding to account for species richness size spectra on the basis that the number of species is likely to increase with the number of specimens examined, suggesting that bimodal species size distributions are another potential artefact. He stated that this calls into question accepted ideas that meiobenthos and macrobenthos have coherent identities with distinct ecological attributes and went on to conclude that a single mathematical formulation of standing stock and body size might be appropriate for biogeochemical modelling purposes.

\section{Real size spectra}

Nearly 30 years ago, before the ready availability of computer simulation, Warwick (1984) addressed the problem of potential sampling artefacts in the above context. In studies of species richness size spectra from 8 locations (examples in Fig. 1), more than 2 mesh sizes were used for the extraction of the fauna in all but one case (Northumberland offshore mudi details in Warwick 1984). At 5 locations, mesh 


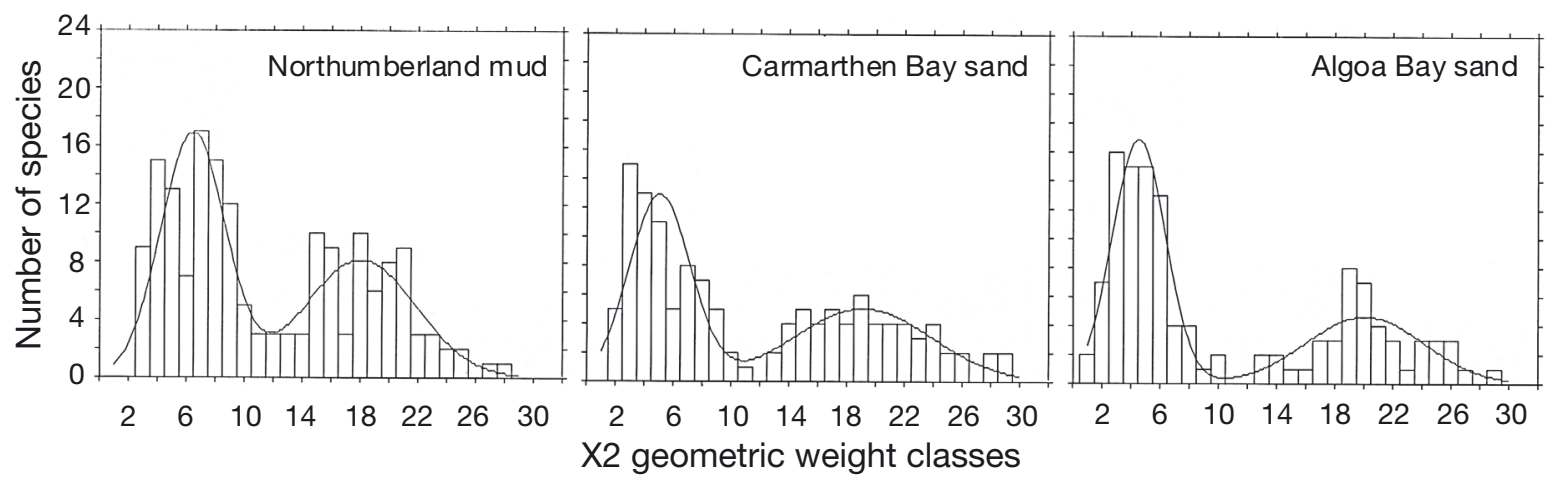

Fig. 1. Examples of species richness size spectrum histograms for sublittoral samples of metazoan benthos, showing conservative pattern of 2 normal curves separated by a trough (redrawn from Warwick 1984)

sizes of 63,125 and $500 \mu \mathrm{m}$ were used, the intermediate size employed specifically to enumerate species of intermediate size between meiobenthos and macrobenthos. Interestingly, the size spectrum from subtidal sand in Algoa Bay, South Africa (Fig. 1) was based on mesh sizes of 63, 180, 1000 and $1300 \mu \mathrm{m}$ with additional hand collection by divers, which is quite similar to the 4 -sieve scheme simulated in Bett's (2013) Fig. 4 (63, 180, 500 and $1400 \mu \mathrm{m})$. Bett's simulated data matched the size continuum with no trough between meiobenthos and macrobenthos, while the real data (Warwick 1984) conformed to the highly conservative bimodal pattern found at all locations. Furthermore, Warwick (1984) also considered the possible relationship between numbers of individuals and numbers of species: For each sample series and each mesh size, a sufficient number of samples was analysed for the species numbers to reach an acceptable asymptote, so that a relatively large number of additional samples would have needed to be examined to add an appreciable number of species. Bett's (2013) proposition that this conservative bimodal pattern is the result of a sampling artefact is therefore unacceptable. Bett's simulations also fail to explain the fact that this pattern is modified by water depth and disturbance: The proportion of macrofauna species increases from disturbed intertidal situations to more stable deeper water (Warwick 1984), and mechanisms of resource partitioning and diversity maintenance in the meiobenthos and macrobenthos may be affected differentially by sediment disturbance (Warwick et al. 1990).

\section{Meiobenthos and macrobenthos as discrete entities}

Most controversial is Bett's (2013) questioning of the well-established view that meiobenthos and macrobenthos are discrete coherent entities each with dis- tinct ecological attributes, since this contradicts what is known about size-related biological traits of benthic metazoans. Despite differences in sampling protocols, sediment types and the sets of sieve sizes employed, the species size spectra shown in Fig. 1 are remarkably conservative, with 2 separate lognormal distributions having modes at dry body weights of $0.64 \mu \mathrm{g}$ and $3.2 \mathrm{mg}$ and a trough between them at $45 \mu \mathrm{g}$. There are no statistically significant differences at the $5 \%$ level in the values of these parameters among locations (Clarke 1984). The form of these lognormal curves is different from Bett's (2013) flattopped spectra for each of the 2 sieve sizes, with the flat tops reflecting the underlying simulated size distribution. Because the pattern is so conservative, Warwick (1984) concluded that it resulted from evolutionary mechanisms that determine the size structure of the regional species pool. This explanation was predicated by the early observation of Hutchinson \& MacArthur (1959 p. 121) that

The ordinary symmetrical logarithmic curve we take to imply that a given type of organization implies a certain class of particularly appropriate niches and that as more extreme niches are occupied the amount of evolutionary displacement needed is about as easy to achieve, with a given type of organization, by change in size of a given factor in either direction. [emphasis added]

Warwick (1984) thus postulated that 2 separate lognormal distributions would result if there were 2 more or less separate types of organisation with no intermediates. Contrary to Bett's (2013) assertion, many, if not most, functional traits of marine benthic animals switch at about $45 \mu$ dry weight (Table 1 ; see Warwick 1984 for discussion of further implications of this phenomenon). Credence to this explanation based on 2 levels of functional organisation is provided by the fact that, in freshwater sediments, the meiofauna-macrofauna dichotomy does not seem to exist, since the species size spectrum is unimodal 
Table 1. Size related biological traits that switch abruptly at about $45 \mu \mathrm{g}$ dry weight (final adult body size) in temperate shallow water marine benthos (from Warwick 1984)

\begin{tabular}{|lll|}
\hline & Less than $45 \mu \mathrm{g}$ & More than $45 \mu \mathrm{g}$ \\
\hline Development & Direct benthic & Planktonic \\
Dispersal & As adults & Planktonic larvae \\
Generation time & Less than 1 yr & More than 1 yr \\
Reproduction & Semelparous & Iteroparous (usually) \\
Feeding & Discriminate use of & Indiscriminate use of \\
& particles & particles \\
Resource & Particle selection & Spatial segregation and \\
partitioning & (size, shape, quality) & particle size selection \\
Growth & Reach asymptotic & Continue growth \\
& adult size & throughout life \\
Mobility & Motile & Sedentary or motile \\
\hline
\end{tabular}

(Strayer 1986, Stead et al. 2005). However, the reproductive characteristics of the species involved are very different: While most shallow-water temperate marine macrobenthos have planktonic larvae, many species in the freshwater benthos are the larval stages of flying insects (Lopez 1988). Unimodal relationships of body size and diversity, with most species being of intermediate size, occur globally, regionally and locally in many environments and can be explained by models that incorporate biological traits (Fenchel 1993, Siemann et al. 1996, Etienne \& Olff 2004), but not by those based on the mechanics of inert particles.

Apart from the dichotomy of functional traits between meiobenthos and macrobenthos, community organisation and responses to environmental per-

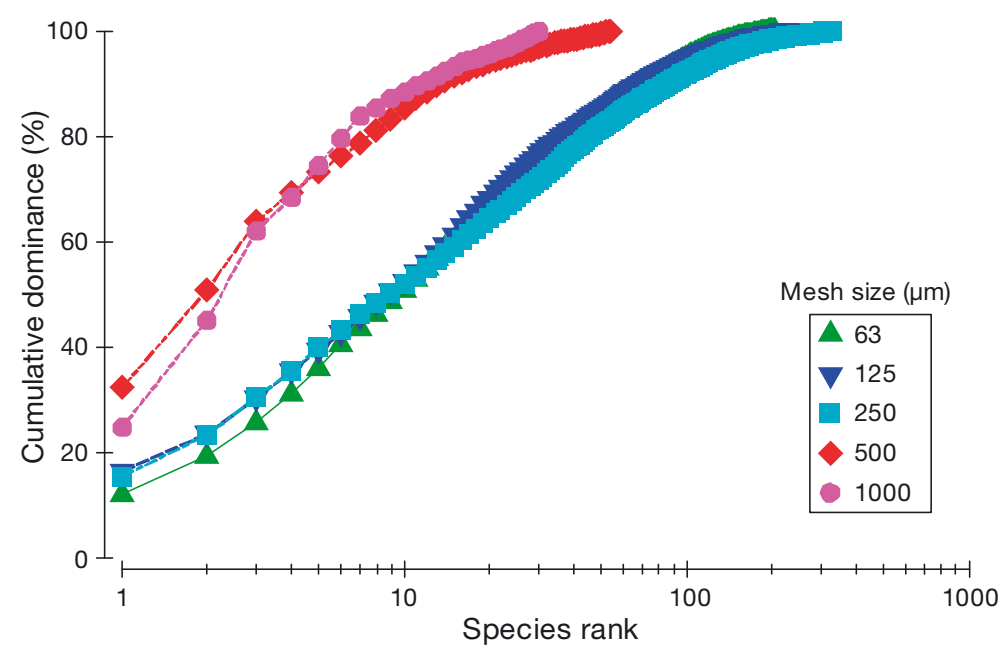

Fig. 2. k-dominance curves for benthic species sampled with sieves of 5 mesh sizes on St Martin's Flats, Isles of Scilly, UK, showing coherence of curves for macrobenthos $(1000$ and $500 \mu \mathrm{m})$ and meiobenthos $(250,125$ and $63 \mu \mathrm{m}$ ) but a big difference between the two (redrawn from Warwick et al. 2006) turbation in terms of species body size are also distinctly different. Using a series of samples sieved using 5 mesh sizes $(63,125$, 250, 500 and $1000 \mu \mathrm{m})$, Warwick et al. (2006) showed that diversity profiles were very consistent within the size classes of meiobenthos and macrobenthos of an intertidal sand-flat, regardless of the mesh size used to extract the fauna, but were very different between these 2 categories (Fig. 2). Bett's theory would predict a gradual change in species composition when sampling a continuum of body sizes using a series of sieves with increasing mesh size, since different life stages of each species would be captured by more than 1 sieve size. However, Warwick et al. (2006) demonstrated a dramatic change in species composition at the meiofauna-macrofauna size boundary (250 to $500 \mu \mathrm{m})$, with only small gradual changes within the meiobenthic and macrobenthic size ranges (Fig. 3). Furthermore, high levels of organic enrichment result in dramatic increases in abundance of the largest species of meiobenthos, mainly oncholaimid nematodes and harpacticoid copepods of the genera Tisbe and Bulbamphiascus, and the smallest representatives of the macrofauna, mainly small annelids (Warwick 2007). The body size of these species falls within the trough between the meiofauna and macrofauna adult body-size distributions, and in these 'enrichment communities' of opportunistic species the meiofauna-macrofauna traits dichotomy does not apply; all the species have direct benthic development and are non-selective deposit feeders with approximately the same lifespan, possibly resulting in a breakdown of the bimodal body-size distribution.

Bett (2013) states that a single benthic standing stock and body size formulation is an attractive prospect for biogeochemical modelling. Biogeochemical models aim to model biogeochemistry. Generally such models are not size-based, and a model may be formulated in any way that makes sense to the modeller and in the context of the purposes for which the model is constructed. Ecological models are more complex, aiming to model ecosystem components, and in such models biogeochemistry becomes an emergent property. The case for meiobenthos and macrobenthos being 'coherent entities with distinct ecological attributes' (Bett 2013, p. 1) is overwhelming, despite Bett's assertions to 


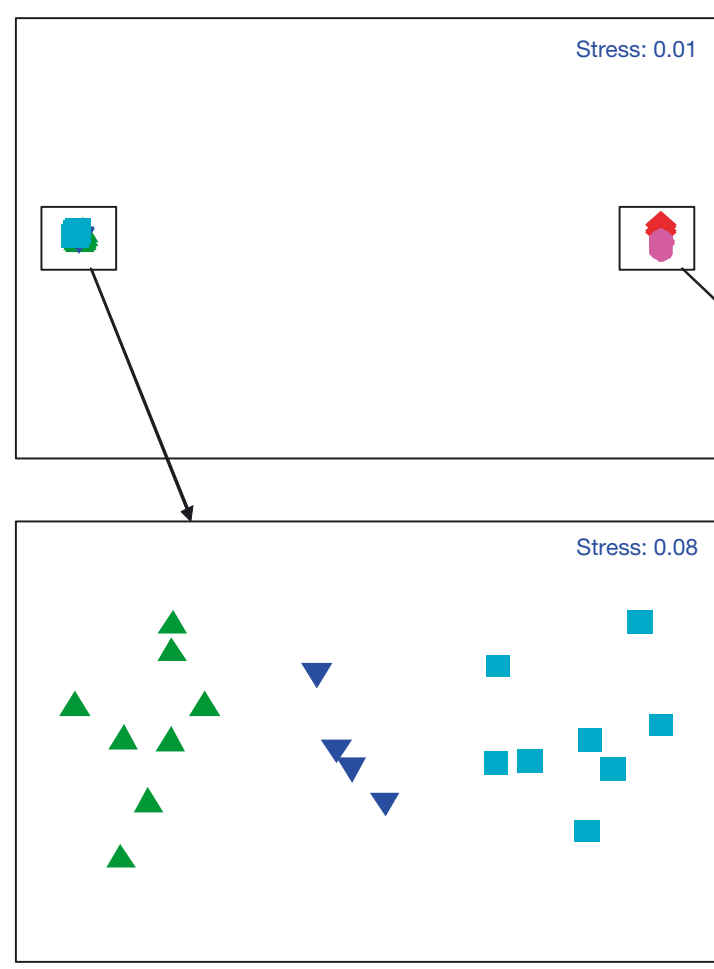

the contrary. Regarding them as a single entity in any kind of ecological modelling seems inappropriate, and the specific functional traits discriminating macrobenthos and meiobenthos should be retained.

Acknowledgements. I acknowledge my Honorary Research Fellowships at the Plymouth Marine Laboratory and my Adjunct Professorship and Sir Walter Murdoch Distinguished Collaborator appointment at Murdoch University. I am grateful to my colleague Paul Somerfield for helpful discussions.

\section{LITERATURE CITED}

Bett BJ (2013) Characteristic benthic size spectra: potential sampling artefacts. Mar Ecol Prog Ser 487:1-6

Clarke KR (1984) Parameter estimation for mixture distributions of species size. Oecologia 61:40-41 (separately authored appendix to Warwick 1984)

Etienne RS, Olff H (2004) How dispersal limitation shapes species-body size distributions in local communities. Am Nat 163:69-83

Fenchel T (1993) There are more small than large species? Oikos 68:375-378

Hutchinson GE, MacArthur RH (1959) A theoretical ecolog-

Editorial responsibility: Charles Peterson,

Morehead City, North Carolina, USA
Fig. 3. MDS plots using standardised square root transformed abundance data and Bray-Curtis similarity for the benthic species from sieves of 5 mesh sizes on St Martin's Flats, showing abrupt change in species composition between 250 and $500 \mu \mathrm{m}$ (redrawn from Warwick et al. 2006) ical model of size distributions among species of animals. Am Nat 93:117-125

Lopez GR (1988) Comparative ecology of the macrofauna of freshwater and marine muds. Limnol Oceanogr 33: 946-962

Siemann E, Tilman D, Haarstad J (1996) Insect species diversity, abundance and body size relationships. Nature 380:704-706

Stead TK, Schmid-Araya JM, Schmid PE, Hildrew AG (2005) The distribution of body size in a stream community: one system, many patterns. J Anim Ecol 74:475-487

Strayer D (1986) The size structure of a lacustrine zoobenthic community. Oecologia 69:513-516

Warwick RM (1984) Species size distributions in marine benthic communities. Oecologia 61:32-41

Warwick RM (2007) Body size and diversity in marine systems. In: Hildrew AG, Raffaelli DG, Edmonds-Brown R (eds) Body-size: the structure and function of aquatic ecosystems. Cambridge University Press, Cambridge, p 210-224

> Warwick RM, Platt HM, Clarke KR, Agard J, Gobin J (1990) Analysis of macrobenthic and meiobenthic community structure in relation to pollution and disturbance in Hamilton Harbour, Bermuda. J Exp Mar Biol Ecol 138: 119-142

> Warwick RM, Dashfield SL, Somerfield PJ (2006) The integral structure of a benthic infaunal assemblage. J Exp Mar Biol Ecol 330:12-18

Submitted: January 17, 2014; Accepted: April 23, 2014 Proofs received from author(s): April 30, 2014 